\title{
WNT5A Inhibits Hepatocyte Proliferation and Concludes $\beta$-Catenin Signaling in Liver Regeneration
}

Jing Yang, ${ }^{*}$ Antonella Cusimano, ${ }^{* \dagger \ddagger}$ Jappmann K. Monga, ${ }^{*}$ Morgan E. Preziosi, ${ }^{*}$ Filippo Pullara, ${ }^{\dagger \S}$ Guillermo Calero, Richard Lang, "Terry P. Yamaguchi, "Kari N. Nejak-Bowen, ${ }^{*}$ and Satdarshan P. Monga*,**

From the Departments of Pathology, * Structural Biology, ${ }^{\S}$ and Medicine, ** University of Pittsburgh School of Medicine, Pittsburgh, Pennsylvania; the Ri.MED Foundation, ${ }^{\dagger}$ Palermo, Italy; the Institute of Biomedicine and Molecular Immunology Alberto Monroy, ${ }^{\ddagger}$ National Research Council, Palermo, Italy; the Visual Systems Group, "Cincinnati Children's Hospital Medical Center, Cincinnati, Ohio; and the Cancer and Developmental Biology Laboratory," Center for Cancer Research, National Cancer Institute-Frederick, NIH, Frederick, Maryland

Accepted for publication April 7, 2015.

Address correspondence to Satdarshan P. Monga, M.D., Departments of Pathology and Medicine, University of Pittsburgh School of Medicine, 200 Lothrop St, Rm S-422 BST, Pittsburgh, PA 15261. E-mail: smonga@pitt.edu.

\begin{abstract}
Activation of Wnt/ $\beta$-catenin signaling during liver regeneration (LR) after partial hepatectomy (PH) is observed in several species. However, how this pathway is turned off when hepatocyte proliferation is no longer required is unknown. We assessed LR in liver-specific knockouts of Wntless (WLs-LKO), a protein required for Wnt secretion from a cell. When subjected to $\mathrm{PH}$, Wls-LKO showed prolongation of hepatocyte proliferation for up to 4 days compared with littermate controls. This coincided with increased $\beta$-catenin-T-cell factor 4 interaction and cyclin-D1 expression. WLs-LKO showed decreased expression and secretion of inhibitory Wnt5a during LR. Wnt5a expression increased between 24 and 48 hours, and Frizzled-2 between 24 and 72 hours, after PH in normal mice. Treatment of primary mouse hepatocytes and liver tumor cells with Wnt5a led to a notable decrease in $\beta$-catenin-T-cell factor activity, cyclin-D1 expression, and cell proliferation. Intriguingly, Wnt5a-LKO did not display any prolongation of LR because of compensation by other cells. In addition, Wnt5a-LKO hepatocytes failed to respond to exogenous Wnt5a treatment in culture because of a compensatory decrease in Frizzled-2 expression. In conclusion, we demonstrate Wnt5a to be, by default, a negative regulator of $\beta$-catenin signaling and hepatocyte proliferation, both in vitro and in vivo. We also provide evidence that the Wnt5a/Frizzled-2 axis suppresses $\beta$-catenin signaling in hepatocytes in an autocrine manner, thereby contributing to timely conclusion of the LR process. (Am J Pathol 2015, 185: 2194-2205; http:// dx.doi.org/10.1016/j.ajpath.2015.04.021)
\end{abstract}

Other than its roles in hepatic development, metabolic zonation, and hepatocarcinogenesis, $\beta$-catenin signaling plays an important role in liver regeneration (LR). ${ }^{1}$ Liver is a unique organ in its ability to respond physiologically through non-stem cell-dependent regeneration after surgical or toxin-induced loss of hepatic mass. ${ }^{2}$ After partial hepatectomy $(\mathrm{PH})$, several signaling pathways get activated in tandem to ensure proper initiation and progression of the regenerative process, which entails orderly proliferation of all resident cells of the liver. ${ }^{2}$ One pathway that is activated early during LR is the $\mathrm{Wnt} / \beta$-catenin signaling pathway. This pathway has been shown to be highly relevant in ensuring proper $G_{1}$ to $S$ phase transition of hepatocytes through regulation of its key target, cyclin-D1. ${ }^{3,4}$ In fact, several studies have shown that disruption of $\mathrm{Wnt} / \beta$-catenin signaling in various genetic mouse models leads to blunted LR, although, as many other signaling molecules, $\beta$-catenin too has been deemed redundant because its loss delays, but does not completely prevent, regeneration.

An important attribute of LR is the ability of this process to spontaneously terminate when the normal hepatic mass

Supported by NIH grants 1R01DK62277 and 1R01DK100287 and Endowed Chair for Experimental Pathology (S.P.M.) and Ri.MED grant (A.C.).

J.Y. and A.C. contributed equally to this work.

Disclosures: S.P.M. is a consultant for Abbvie. 
consistent with the prehepatectomy mass is re-established. Because hepatocytes have seemingly unlimited proliferative capacity, ${ }^{5,6}$ there must exist some regulatory mechanisms to stop the LR process. It has been suggested that pathways such as transforming growth factor- $\beta$ signaling may play a role in the termination of LR. ${ }^{7}$ Furthermore, the role of extracellular matrix in regulating hepatocyte proliferation, especially during LR, has also been recently suggested. ${ }^{8}$

We took an alternative approach to address termination mechanisms of LR. We hypothesized that because a series of proproliferative signaling pathways are turned on to initiate LR soon after PH, identification of negative regulators of such signaling mechanisms may yield clues to the overall LR termination processes. Because $\beta$-catenin is a proproliferative signal in LR, identification of what terminates $\beta$-catenin signaling might eventually be contributing to cessation of LR. Interestingly, examination of $\beta$-catenin signaling, cyclin-D1 expression, and markers of $S$ phase in albumin-cre-driven Wntless knockout (KO) or liverspecific KOs of Wntless (Wls-LKO) mice revealed temporal prolongation of the hepatocyte proliferative program. This suggested that hepatocytes might be a source of Wnt that negatively regulates $\beta$-catenin signaling, because Wntless protein is specific for only Wnt secretion. Further analysis revealed Wnt5a to be differentially regulated during LR and contributed to inhibiting $\beta$-catenin activity in primary hepatocytes and liver tumor cells. Intriguingly, liverspecific Wnt5a KO lacked any spontaneous phenotype and displayed normal initiation and termination of LR. This is likely because of adaptive changes such as reduced expression of Frizzled-2 in the Wnt5a-LKO hepatocytes. In conclusion, we demonstrate Wnt5a to be, by default, a negative regulator of $\beta$-catenin signaling and hepatocyte proliferation in vitro and in vivo. Furthermore, we provide evidence that Wnt5a may be one of the effectors that is secreted by hepatocytes to suppress $\beta$-catenin signaling in hepatocytes in an autocrine manner, which, through Frizzled-2, terminates $\beta$-catenin signaling, thereby contributing to timely conclusion of the process of LR.

\section{Materials and Methods}

\section{Mice and Breeding}

To generate liver-specific Wls KO, homozygous Wls floxed mice $\left(\mathrm{Wls}^{f l o x}{ }^{f f l o x}\right)^{9,10}$ were bred with albumin-Cre ${ }^{+-}$mice (Jackson Laboratories, Bar Harbor, ME). ${ }^{11}$ The offspring carrying the floxed $W l s$ allele and albumin-Cre $\left(W l{ }^{f l o x / w t} ; A l b\right.$ $\mathrm{Cr}^{+/-}$) were bred to homozygous $\mathrm{Wls}$ floxed mice $\left(\mathrm{Wls}^{\text {floxflox }}\right)$. Mice with the genotype $\mathrm{Wls}^{\text {floxflox }} ; \mathrm{Alb}-\mathrm{Cre}^{+/-}$represent WlsLKO mice. Mice with the genotypes $\mathrm{Wls}^{\text {floxfflox}} ; \mathrm{Alb}^{\mathrm{CO}} \mathrm{Cr}^{-/-}$and Wls ${ }^{f l o x / w t} ; \mathrm{Alb}-\mathrm{Cre}^{---}$were used as controls.

To generate liver-specific Wnt5a KO mice, homozygous

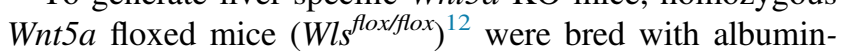
$\mathrm{Cr}^{+/-}$mice. ${ }^{11}$ The offspring carrying the floxed Wnt5a allele and albumin-Cre $\left(W n t 5 a^{f l o x / w t} ; \mathrm{Alb}^{-\mathrm{Cre}^{+/-}}\right)$were bred

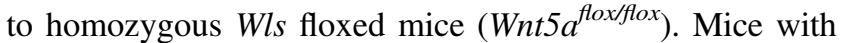
the genotype Wnt5 $a^{f l o x / f l o x} ; \mathrm{Alb}-\mathrm{Cre}^{+/-}$represent Wnt5aLKO mice. Mice with the genotypes Wnt5 $a^{f l o x f f o x} ; \mathrm{Alb}-\mathrm{Cr}^{-/-}$ and $\mathrm{Wnt} 5 a^{f l o x / w t} ; \mathrm{Alb}-\mathrm{Cre}^{-/-}$were used as controls.

\section{Morphometric Analysis}

All experiments on mice were performed under the strict guidelines of the NIH (Bethesda, MD) and the Institutional Animal Use and Care Committee at the University of Pittsburgh (Pittsburgh, PA). Age- and sex-matched conditional KO and control littermates were weighed and sacrificed $(n=3$ to 5). Livers were isolated, and the wet weights were recorded to calculate the liver weight/body weight ratio [(liver weight/ body weight) $\times 100$ ]. The means for the two groups were compared for statistically significant differences by $t$-test.

\section{PH Data}

Twelve-week-old male control (Con) or KO mice were subjected to $\mathrm{PH}^{4}$ Equal numbers of $\mathrm{KO}$ and Con mice were sacrificed by cervical dislocation after isoflurane anesthesia at different time points: 4 hours $(n=3), 24$ hours $(n=3), 40$ hours $(n \geq 3), 3$ days $(n \geq 3), 4$ days $(n=3)$, and 5 days $(n=3)$ after $\mathrm{PH}$. The regenerating livers were harvested and used for protein extraction and paraffin embedding, as described below.

\section{Protein Extraction and Western Blot Analyses}

Whole-cell lysate preparation was performed using radioimmunoprecipitation assay buffer $(9.1 \mathrm{mmol} / \mathrm{L}$ dibasic sodium phosphate, $1.7 \mathrm{mmol} / \mathrm{L}$ monobasic sodium phosphate, $150 \mathrm{mmol} / \mathrm{L}$ sodium chloride, $1 \%$ Nonidet P-40, $0.5 \%$ sodium deoxycholate, and $0.1 \%$ sodium dodecylsulfate, $\mathrm{pH}$ adjusted to 7.4) containing fresh protease and phosphatase inhibitor cocktails (Sigma, St. Louis, MO). Protein (40 to 50 $\mu \mathrm{g})$ was resolved by SDS-PAGE analysis using the miniPROTEIN 3 electrophoresis module assembly (Biorad, Hercules, CA) and transferred to immobilon-polyvinylidene difluoride membranes (Millipore, Billerica, MA). Proteins were detected by SuperSignal West Pico Chemiluminescent Substrate (Thermo Fisher Scientific, Rockford, IL) and visualized by autoradiography.

Primary antibodies used in this study were against $\beta$-catenin (BD Transduction, San Jose, CA); cyclin-D1 (Thermo Fisher Scientific); glutamine synthetase, Frizzled-2, Frizzled-4, and glyceraldehyde-3-phosphate dehydrogenase (Santa Cruz Biotechnology, Dallas, TX); Wnt5a and Ror2 (Cell Signaling); and Wntless and actin (Millipore). Horseradish peroxidase-conjugated secondary antibodies (Millipore) were used at 1:20,000 to 1:50,000 dilutions.

\section{Histology and IHC}

Liver sections from the age- and sex-matched $\mathrm{KO}$ and Con mice were analyzed by immunohistochemistry (IHC) for glutamine 
synthetase (Santa Cruz Biotechnology), Cyp1a2 (Santa Cruz Biotechnology), Cyp2e1 (Millipore), and proliferating cell nuclear antigen (PCNA; Santa Cruz Biotechnology) to determine their expression and/or localization using the indirect immunoperoxidase technique, as described previously. ${ }^{4}$ Briefly, paraffin sections ( $4 \mu \mathrm{m}$ thick) were passed through xylene and graded ethanol, and rinsed in phosphate-buffered saline (PBS). Hydrogen peroxide (3\%; Sigma) was used to inactivate endogenous peroxide. Slides were microwaved in citrate buffer for 8 minutes and blocked in super block (ScyTek Laboratories, Logan, UT) for 10 minutes, followed by a 1-hour incubation at room temperature in the primary antibody. After three washes with PBS, the sections were incubated in the secondary horseradish peroxidase-conjugated antibody (Millipore) for $30 \mathrm{mi}-$ nutes at room temperature, and signal was detected using the ABC Elite kit (Vector Laboratories, Burlingame, CA), following the manufacturer's instructions. Sections were counterstained with Shandon (Thermo Scientific, Fremont, CA) for 1 minute and passed through the dehydration process, followed by coverslipping and mounting using DPX (Fluka Labs, St. Louis, MO). Slides were viewed under an Axioskop 40 (Zeiss, Thornwood, NY) upright research microscope, and digital images were obtained by Nikon Coolpix camera (Nikon, Melville, NY).

For proliferation assay, indirect IHC was performed for PCNA that recognizes cells in the cell cycle. The positive cells were counted in three low-power fields $(\times 200)$ in three sections from three different knockout or control livers. The average numbers of positive cells were compared and statistical assessment was made by the $t$-test. $P<0.05$ was considered significant.

\section{Immunoprecipitation}

Lysate $(500 \mu \mathrm{g})$ in a $1-\mathrm{mL}$ volume (in the presence of protease and phosphatase inhibitors) was precleared using appropriate control $\mathrm{IgG}$ together with $12 \mu \mathrm{L}$ of protein $\mathrm{A} / \mathrm{G}$ agarose for 30 minutes at $4^{\circ} \mathrm{C}$ (Santa Cruz Biotechnology). The supernatant obtained after centrifugation $(1000 \times g)$ at $4^{\circ} \mathrm{C}$ was incubated with primary antibody for overnight at $4^{\circ} \mathrm{C}$ using end-over-end rotation, followed by $20 \mu \mathrm{L}$ of resuspended protein $\mathrm{A} / \mathrm{G}$ agarose for 1 hour. The pellets were collected by centrifugation $(1000 \times g)$ and washed four times for 5 minutes each with radioimmunoprecipitation assay buffer at $4{ }^{\circ} \mathrm{C}$. The pellets were resuspended in an equal volume of standard electrophoresis loading buffer with SDS and fresh $\beta$-mercaptoethanol and boiled for 5 minutes. Samples $(15 \mu \mathrm{L})$ were resolved on ready gels. Antibodies used for immunoprecipitation were mouse anti- $\beta$-catenin (BD Transduction) and rabbit anti-T-cell factor (TCF) 4 (Cell Signaling, Danvers, MA).

\section{Cell Culture and Assays}

The human hepatoblastoma cell line (HepG2) was obtained from ATCC (Manassas, VA). Cells were cultured in Eagle's minimum essential medium (ATCC) supplemented with $10 \%$ fetal bovine serum and incubated in $5 \% \mathrm{CO}_{2}$ at $37^{\circ} \mathrm{C}$. Purified human recombinant Wnt5a was synthesized, as described previously, and HepG2 cells were treated for 48 hours ( $3 \mu \mathrm{g} /$ $\mathrm{mL}){ }^{13}$ Alternatively, the parental L cells (CRL-2648; ATCC) and Wnt5a-expressing L Wnt-5A cells (CRL-2814; ATCC) were cultured in Dulbecco's modified Eagle's medium plus $10 \%$ fetal bovine serum, with or without G-418 (Sigma, St. Louis, MO). Conditioned media were collected as per the suggested protocol. For primary mouse hepatocytes, recombinant mouse Wnt5a (R\&D, Minneapolis, MN) was added to the culture for 48 hours at $500 \mathrm{ng} / \mathrm{mL}$.

For $\beta$-catenin-TCF reporter activity, HepG2 cells plated in six-well plates $\left(3 \times 10^{5}\right.$ per well $)$ were transiently transfected with $0.8 \mu \mathrm{g}$ of TopFlash or FopFlash plasmids (Upstate Biotechnology, Lake Placid, NY) with Lipofectamine 2000 (Invitrogen, Carlsbad, CA) at a ratio of 5:1. To normalize transfection efficiency, cells were cotransfected with $0.2 \mu \mathrm{g}$ of internal control reporter Renilla reniformis luciferase driven under the TK promoter (pRL-TK; Promega, Madison, WI). Luciferase assay was performed using the Dual Luciferase Assay System kit, according to the manufacturer's protocols (Promega, Madison, WI). Relative luciferase activity was reported as a normalized ratio of firefly/renilla luciferase activity. Experiments were performed in triplicate.

To study the role of the Wnt5a-Frizzled-2 axis, HepG2 cells were cotransfected with TopFlash or FopFlash plasmid and cDNA clone green fluorescent protein (GFP)-Tagged Fzd2 (OriGene Technologies, Rockville, MD) or control pcDNA plasmid at a ratio of 5:2. Transfection was monitored by GFP immunofluorescence and was at approximately $30 \%$ after 24 hours of transfection, at which time cells were treated with $3 \mu \mathrm{g} / \mathrm{mL}$ human recombinant Wnt5a or PBS and harvested after 48 hours for analysis of reporter activity, as described above.

Primary mouse hepatocytes from control mice or Wnt5aLKO were isolated by two-step collagenase perfusion, as described elsewhere. ${ }^{13}$ Briefly, an anesthetized mouse was subjected to a midline abdominal incision, and the inferior vena cava was catheterized and the portal vein was severed. After flushing, the liver was perfused gradually with collagenase (Sigma) until uniform discoloration of the liver was apparent. The liver was removed and gently shaken in a sterile container, and hepatocytes were washed and counted. Next, hepatocytes were plated onto collagen-coated six-well plates (BD Biosciences, San Jose, CA) at 250,000 cells per well. After the initial 2-hour attachment period, the hepatocytes were cultured in basal hepatocyte growth medium alone or supplemented with $40 \mathrm{ng} / \mathrm{mL}$ hepatocyte growth factor and $20 \mathrm{ng} / \mathrm{mL}$ epidermal growth factor (R\&D). In addition, mouse recombinant Wnt5a (R\&D) was added at $500 \mathrm{ng} / \mathrm{mL}$ to half the wells.

A tritium $\left(\left[{ }^{3} \mathrm{H}\right]\right)$ thymidine uptake assay was performed, as previously described, ${ }^{13}$ on HepG2 cells treated with recombinant human Wnt5a or Wnt5a-conditioned media and 
primary mouse hepatocytes cultured in the presence of recombinant mouse Wnt5a to determine an impact on cell proliferation. Briefly, HepG2 cells were grown to approximately $50 \%$ confluence, at which time Wnt5a was added to the cultures along with $2.5 \mu \mathrm{Ci} / \mathrm{mL}\left[{ }^{3} \mathrm{H}\right]$ thymidine. These cells were cultured for $\left[{ }^{3} \mathrm{H}\right]$ thymidine incorporation for 40 to 48 hours, as indicated in Results. Next, the cells were washed with $0.9 \% \mathrm{NaCl}$ and lysed in $0.2 \%$ SDS, $1 \times$ standard saline citrate $(150 \mathrm{mmol} / \mathrm{L} \mathrm{NaCl}$ and $15 \mathrm{mmol} / \mathrm{L}$ Na-citrate, $\mathrm{pH} 7.0$ ), and $5 \mathrm{mmol} / \mathrm{L}$ EDTA, and aliquots were used to determine $\left[{ }^{3} \mathrm{H}\right]$ thymidine incorporation on a Beckman scintillation counter (Beckman, Brea, CA). Counts from the experiments performed in triplicate from each group were compared for statistical significance with $t$-test. $P<0.05$ was considered significant.

\section{RNA Isolation and qPCR}

Cellular RNA was obtained by micro RNA isolation kit (Thermo Scientific). Total RNA was reverse transcribed after DNase treatment using the TURBO DNase Kit (Thermo Scientific), as per the manufacturer's instructions. The RNA was used for quantitative PCR (qPCR) analysis on a StepOne Plus using $2 \times$ SYBR Green PCR Master Mix (Applied Biosystems, Foster, CA). The comparative $\Delta \Delta \mathrm{Ct}$ (cycle threshold) method was used for analysis of the data, and calculations were made with the StepOne software version 2 (Applied Biosystems, Grand Island, NY). The primers used in the study are as follows: mouse Wnt5a forward primer $5^{\prime}$ GTCCTTTGAGATGGGTGGTATC-3', Wnt5a reverse primer 5'-ACCTCTGGGTTAGGGAGTGTCT-3', Gapdh forward primer $5^{\prime}$-ACCCAGAAGACTGTGGATGG- $3^{\prime}$ and Gapdh reverse primer 5'-CACATTGGGGGTAGGAACAC3', or Gapdh forward primer 5'-AACTTTGGCATTGTGGAAGG-3' and Gapdh reverse primer $5^{\prime}$-ACACATTGGGGGTAGGAACA-3', Frizzled-4 forward primer 5'-ACCCTAGCAGTCCATCCCTC-3', Frizzled-4 reverse primer $5^{\prime}$ ATAGGGAATGCGGTAAGGCG-3', Frizzled-2 forward primer 5'-GACTCGTTTTGCCCGTCTCT-3', and Frizzled-2 reverse primer $5^{\prime}$-CGAAATCGCTGCATGTCCAC-3'. For human cell line, the real-time primers for Wnt5a and Frizzled2 genes (QuantiTect PCR) were purchased from Qiagen (Valencia, CA) and used as per the manufacturer's recommendations. qPCR was also performed for the reference gene phosphoglycerokinase using the forward primer $5^{\prime}$-GCAGATTGTTTGGAATGGTC- $3^{\prime}$ and the reverse primer $5^{\prime}$ TGCTCACATGGCTGACTTTA- $3^{\prime}$, obtained from Real Time Primers, LLC (Elkins Park, PA).

\section{ELISA}

Forty-eight hours after $\mathrm{PH}$, liver was perfused and hepatocytes were cultured for 24 hours. Conditioned medium was collected and concentrated by centrifugal filter devices (Millipore). The Wnt5a level was measured by the mouse Wnt5a enzyme-linked immunosorbent assay (ELISA) kit
(CUSABIO, Wuhan, China). Experiments were performed according to the manufacturer's instructions. In short, standards and samples were loaded to 96-well microplates precoated with antibody specific for Wnt5a, and incubated for 2 hours at $37^{\circ} \mathrm{C}$. After aspirating each well, the plate was incubated with biotin-conjugated antibody specific for Wnt5a for 1 hour at $37^{\circ} \mathrm{C}$. After washing, avidin-conjugated horseradish peroxidase was added to the wells, incubated for 1 hour at $37^{\circ} \mathrm{C}$. After a wash to remove any unbound avidinenzyme reagent, a substrate solution was added to the wells and incubated for 15 to 30 minutes at $37^{\circ} \mathrm{C}$ to induce a color reaction. The reaction was stopped by adding Stop Solution (CUSABIO) to each well. A microplate reader at $450-\mathrm{nm}$ wavelength was used to determine the optical density of each well, and dilution coefficient was applied for calculating final concentration. An ELISA was performed on two Con and two Wls-LKO mice, and each sample was tested in triplicate.

\section{Results}

\section{LR Is Temporally Enhanced in Wls-LKO after PH}

We have recently reported the generation of Wls-LKO by interbreeding Wntless floxed and Alb-cre transgenic mice. ${ }^{10}$ These mice have an impaired ability to secrete all Wnt proteins from hepatocytes and cholangiocytes. We showed that after $\mathrm{PH}$, there is normal initiation of LR in these mice because comparably high numbers of hepatocytes in S phase were detected at 40 hours. To address the progression of LR, we examined additional time points after $\mathrm{PH}$. The numbers of hepatocytes in S phase by PCNA IHC at 3 days after PH were high in both groups, but the numbers consistently exceeded in Wls-LKO than littermate Con (Figure 1A). Intriguingly, 4 days after PH, when LR had already attenuated in Con, suggested by few PCNA-positive hepatocytes, notably higher numbers were observed in the Wls-LKO (Figure 1A). However, 5 days after $\mathrm{PH}$, both groups showed only occasional PCNA-positive hepatocytes (Figure 1A). No hepatocyte proliferation was evident at 14 days in either group, as reported elsewhere. ${ }^{10}$ Quantification of staining showed a significant increase in the numbers of PCNA-positive hepatocytes in Wls-LKO compared with Con at 3 and 4 days only (Figure 1B). Consistent with these observations, Western blot analyses showed higher levels of cyclin-D1 in Wls-LKO at 3 and 4 days after $\mathrm{PH}$, and with only minor differences evident between the two groups at 5 days (Figure 1C).

Because we and others have shown cyclin-D1 during LR to be predominantly regulated by $\beta$-catenin-TCF4 activation, ${ }^{4,10}$ which is temporal and usually precedes cyclin-D1 protein increases by approximately 24 hours, we next investigated if any changes in this complex were evident during LR in Wls-LKO versus Con mice. Indeed, immunoprecipitation showed enhanced $\beta$-catenin-TCF4 binding in the Wls-LKO livers at both 40 hours and 3 days after $\mathrm{PH}$, suggesting that there is continued $\beta$-catenin activation and 

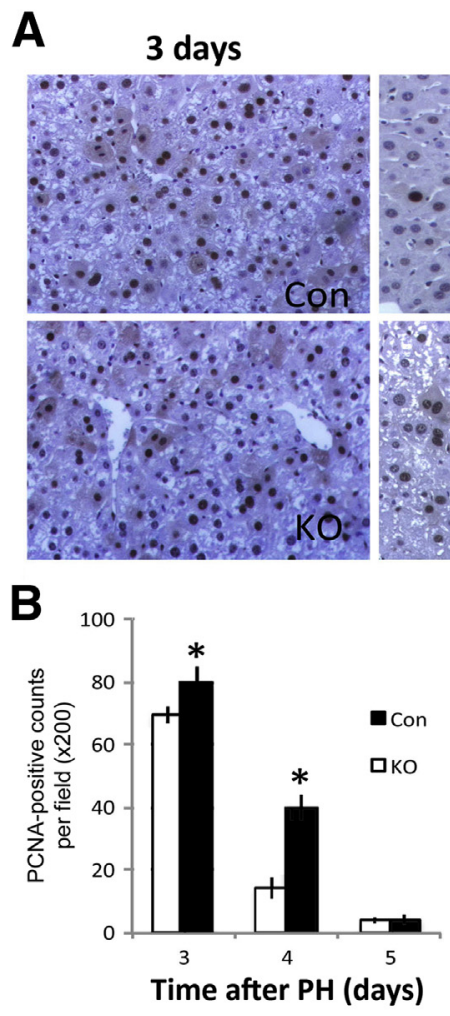

4 days

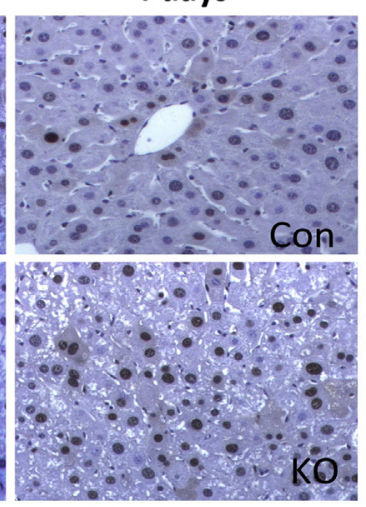

C

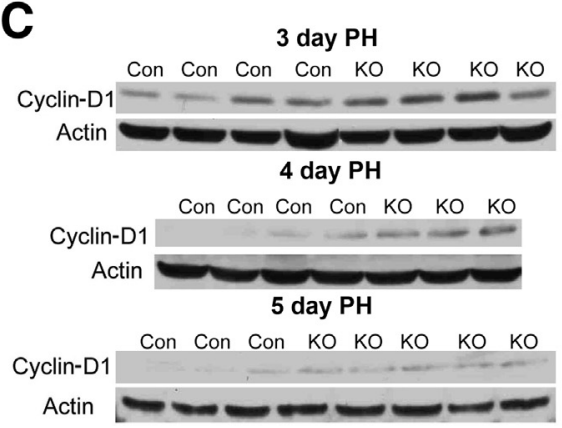

Figure 1 Liver regeneration is temporally prolonged in liver-specific knockouts of Wntless (Wls-LKO) after partial hepatectomy (PH). Immunohistochemistry (IHC) for proliferating cell nuclear antigen (PCNA) shows many positive cells at 3 to 4 days after PH in WIs-LKO (A), confirmed by the quantification of PCNA staining (B). C: A representative Western blot analysis shows higher cyclin-D1 expression in the WIs-LKO livers at 3 and 4 days after $\mathrm{PH}$, with only minor differences evident at 5 days. D: Immunoprecipitation shows enhanced $\beta$-catenin and T-cell factor (TCF) 4 binding in WIs-LKO at 40 hours and 3 days after $\mathrm{PH}$ compared with control (Con). ${ }^{*} P<0.05$. Original magnification, $\times 200(\mathbf{A})$.

D

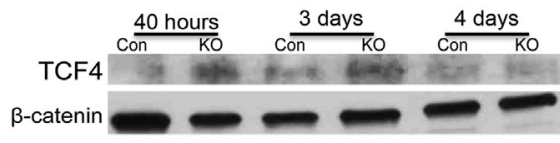

hence a delay in the termination of active $\beta$-catenin signaling in the Wls-LKO (Figure 1D).

\section{Wnt5a and Frizzled-2 Expression Increases Temporally during LR}

Given the fact that hepatocytes in Wls-LKO lack capacity to secrete Wnt proteins only, we next hypothesized that the defect in termination of active $\beta$-catenin signaling leading to continued hepatocyte proliferation at late time points during LR is because of the absence of secretion of an inhibitory Wnt protein from hepatocyte. Because Wnt5a and Wnt11 are two classic noncanonical Wnt ligands that have been shown to have an antagonistic role on $\mathrm{Wnt} / \beta$-catenin signaling, we next determined their expression during LR after $\mathrm{PH}$ in wild-type mice compared with the corresponding sham controls. ${ }^{14,15}$ Indeed, Wnt5a RNA and protein expression, but not Wnt11, increased at 1 to 3 days after $\mathrm{PH}$ (data not shown) (Figure 2, A and C). Because Wnt5a has been classically shown to inhibit $\beta$-catenin signaling via Frizzled-2, we next examined any changes in its expression after PH. ${ }^{16}$ A notable increase in Frizzled-2 RNA and protein expression was noted at days 1 to 3 after $\mathrm{PH}$, suggesting an active Wnt5a-Frizzled-2 axis during these times of LR (Figure 2, B and C).

Because $\beta$-catenin activation is evident in murine regenerating livers at 1 to 6 hours after $\mathrm{PH}^{10}$ and because Wnt5a can induce or suppress $\beta$-catenin activity, depending on the receptor context, ${ }^{17}$ we next tested if Wnt5a could be activating $\beta$-catenin at early stages of LR. We examined expression of Wnt5a, Frizzled-2, and Frizzled-4 at 1 to 24 hours after $\mathrm{PH}$ and found a small, but significant, increase in Wnt5a at 1 and 12 hours after PH (Figure 2D). However, there was no change in the expression of either of the two Frizzled genes at 1 hour, whereas there was a significant decrease in their expression at other times. It was only at 24 hours that an increase in the gene expression of both Wnt5a and Frizzled-2 was simultaneously observed.

Next, we examined Wnt5a levels in Wls-LKO during LR. Intriguingly, lower protein levels of Wnt5a are evident in $W l s$-LKO at both 2 and 3 days after PH (Figure 2E). Because it is only the Wnt-secreting capacity of hepatocytes that is lost in the Wls-LKO mice, the decreased expression may suggest feedback inhibition from Wnt5a accumulation in hepatocytes. To further substantiate the absence of secreted Wnt5a in Wls-LKO and Con, we performed PH on $W l s$-LKO and Con, and 2 days after the procedure, we isolated hepatocytes by collagenase perfusion. Hepatocytes from both groups of mice were cultured for 24 hours, and conditioned media were subjected to ELISA for Wnt5a. A decrease in Wnt5a by approximately $60 \%$ was evident in the media from cultured regenerating hepatocytes from $\mathrm{Wls}$ LKO compared with Con (Figure 2F). These data show that Wnt5a from hepatocytes may be contributing to terminating $\beta$-catenin signaling after hepatocyte proliferation, which is not required during LR, and inability of hepatocytes to secrete this protein may be a possible mechanism of prolongation in hepatocyte proliferation after $\mathrm{PH}$. 

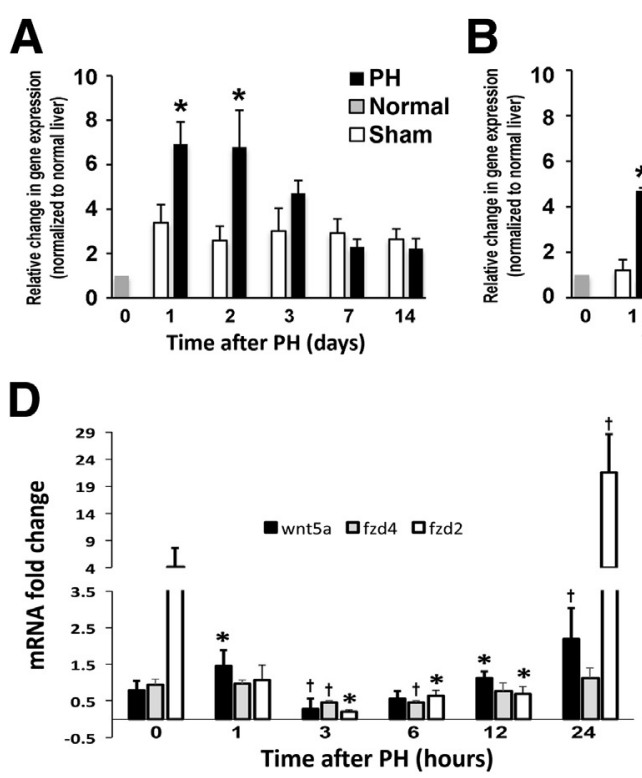
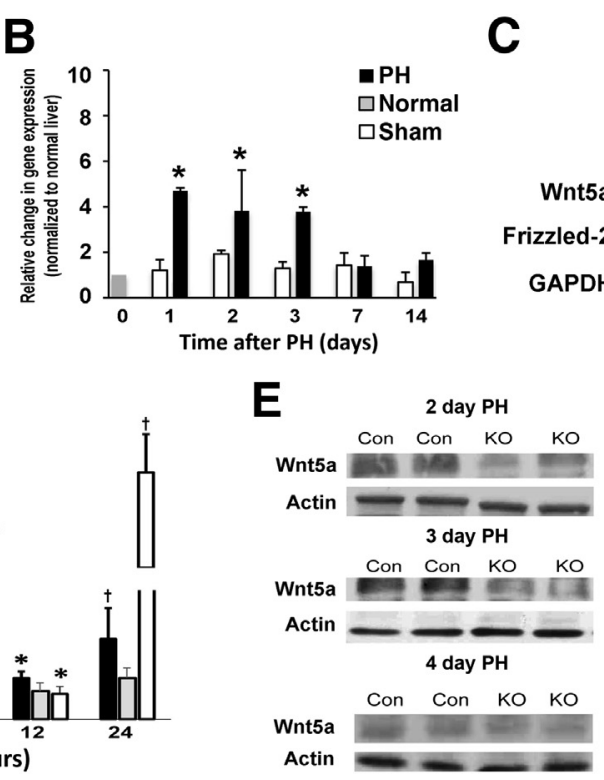

C
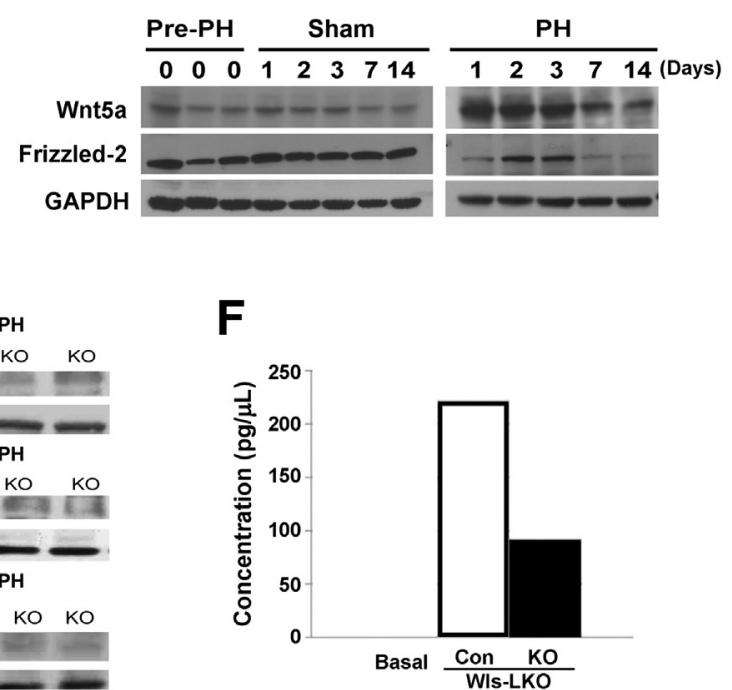

Figure 2 Real-time quantitative PCR ( $9 P C R)$ analysis shows a significant increase in Wnt5a expression at 24 and 48 hours (A) and Frizzled-2 expression at 24 , 48, and 72 hours (B) after partial hepatectomy (PH) compared with shams. C: A representative Western blot analysis shows increased expression of Wnt5a and Frizzled-2 at 24 to 72 hours after PH compared with shams. Comparable protein loading was verified by glyceraldehyde-3-phosphate dehydrogenase (GAPDH). The exposure times for the representative blots were normalized on the basis of a common protein on both gels to ensure comparison. D: qPCR analysis shows changes in Wnt5a, Frizzled-2, and Frizzled-4 mRNA expression at early time points after PH (1, 3, 6, 12, and 24 hours). A significant increase in Wnt5a is observed at 1 and 12 hours; Frizzled-2 expression does not increase at these time points. At 24 hours, a significant concomitant increase in Wnt5a and Frizzled-2 is observed. Frizzled-4 levels do not show an increase. E: Western blot from two representative control (Con) and liver-specific knockouts of Wntless (Wls-LKO) livers show a notable decrease in Wnt5a in the Wls-LKO at 2 and 3 days after PH compared with controls. Equal loading was verified by $\beta$-actin. F: An enzyme-linked immunosorbent assay (ELISA) was performed on conditioned media collected after 24 hours' culture of hepatocytes isolated from regenerating Con and Wls-LKO livers at 48 hours after $\mathrm{PH}$. A representative ELISA shows approximately $60 \%$ decrease in the Wnt5a concentration in the conditioned medium collected from Wls-LKO hepatocytes compared with Con. ${ }^{*} P<0.05$ versus respective sham control (A and $\left.\mathbf{B}\right)$ or versus baseline ( 0 hours; $\left.\mathbf{D}\right) ;{ }^{\dagger} P<0.005$ versus baseline ( 0 hours; $\left.\mathbf{D}\right)$.

\section{Wnt5a Inhibits $\beta$-Catenin Expression and Activity in Primary Hepatocytes and HepG2 Cells}

To directly address the effect of Wnt5a on $\beta$-catenin in liver cells, HepG2 cells transfected with either TopFlash or FopFlash reporter plasmids were treated with purified human recombinant Wnt5a at $3 \mu \mathrm{g} / \mathrm{mL}$ for approximately 48 hours. The biologically active human recombinant Wnt5a was produced using a recently published procedure. ${ }^{18} \mathrm{HepG} 2$ cells are a human hepatoblastoma cell line with exon-3 deletion in the $C T N N B 1$ gene, making $\beta$-catenin constitutively active. Wnt5a treatment led to a significant decrease in TopFlash reporter activity compared with PBS treatment, whereas FopFlash was low and unchanged after Wnt5a or PBS treatment (Figure 3A). HepG2 cells were also cultured for 48 hours in the presence of control media or Wnt5a-conditioned media derived from L cells transfected with Wnt5a or control plasmids (ATCC) at different concentrations. Similar to recombinant Wnt5a treatment, conditioned media led to a dosedependent decrease in TopFlash reporter activity (data not shown) and thymidine incorporation as a measure of DNA synthesis and hence cell proliferation (Figure 3B).

Because during LR, we found an up-regulation of both Wnt5a and Frizzled-2, we next addressed their combined role on $\beta$-catenin activity and proliferation in cell culture. We transiently cotransfected HepG2 cells with Frizzled-2-GFP expression plasmid or control expression vector and
TopFlash reporter and treated cells with purified human recombinant PBS or $3 \mu \mathrm{g} / \mathrm{mL}$ Wnt5a protein to assess impact on reporter activity or DNA synthesis. Frizzled-2 expression was monitored by immunofluorescence for GFP expression and showed successful transfection in approximately $30 \%$ of cells after 24 hours of transfection (Figure 3C). Although Wnt5a treatment or Frizzled-2 expression alone led to a significant decrease in TopFlash reporter activity, the combination led to a synergistic decrease in TopFlash reporter activity (Figure 3C). Furthermore, Wnt5a treatment of Frizzled-2-expressing HepG2 cells led to a more pronounced decrease in cell proliferation compared with control or either treatment by itself, as assessed by thymidine incorporation (Figure 3D).

Last, we determined the impact of Wnt5a on proliferation of primary murine hepatocytes. Hepatocytes were freshly isolated using collagenase perfusion and cultured in the presence of either mouse growth medium with or without growth factors in the presence of $500 \mathrm{ng} / \mathrm{mL}$ of recombinant mouse Wnt5a. Wnt5a treatment for 48 hours led to a significant decrease in thymidine incorporation in both the presence and absence of hepatocyte growth factor and epidermal growth factor in culture (Figure 3E).

To address any changes in $\beta$-catenin signaling after Wnt5a treatment, whole cell lysates from Wnt5a- and PBS-treated primary mouse hepatocytes for 48 hours were examined for key signaling components. As shown in a representative analysis, 
A

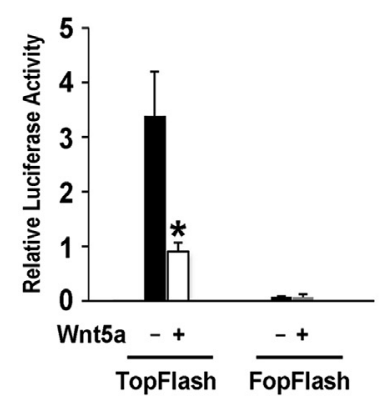

D

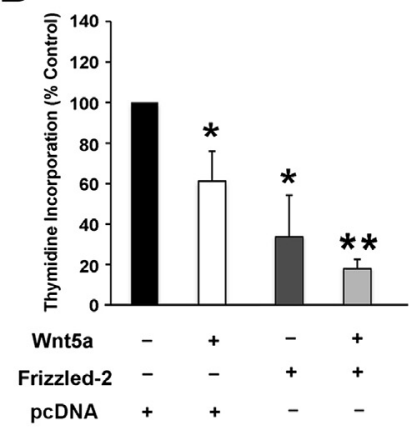

B

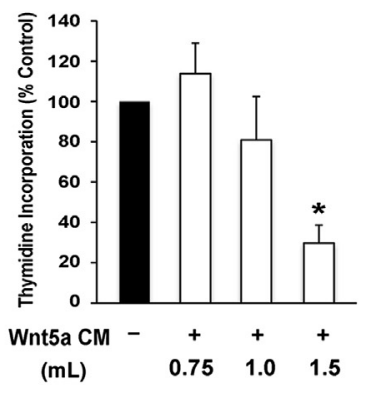

E
C

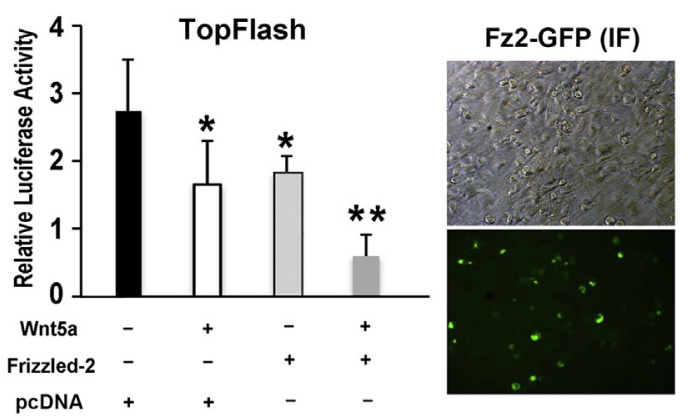

F
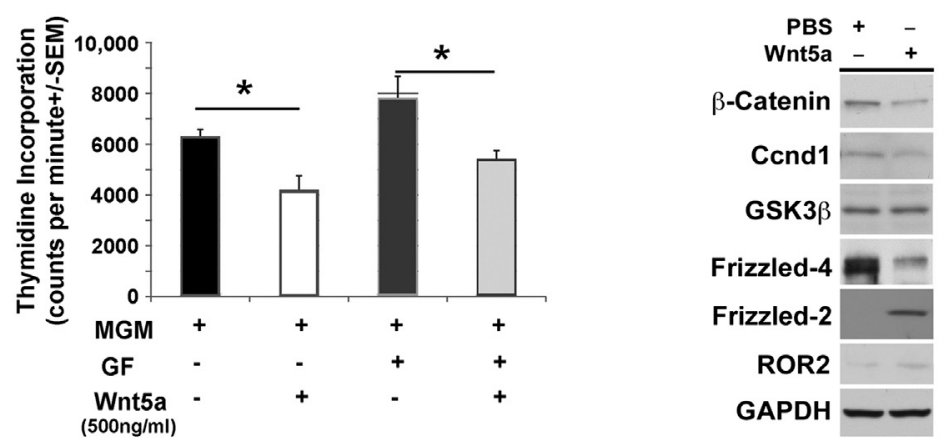

Figure 3 Wnt5a decreases $\beta$-catenin expression and activity and cell proliferation in liver cells. A: Treatment ( 48 hours) with $3 \mu \mathrm{g} / \mathrm{mL}$ human recombinant Wnt5a significantly decreases the TopFlash activity in human hepatoblastoma cell line (HepG2)-treated cells compared with phosphate-buffered saline (PBS). Wnt5a has no effect. B: Wnt5a-conditioned media (CM) derived from L cells show a dose-dependent decrease in HepG2 cell thymidine incorporation compared with treatment with media collected from control L cells. C: Treatment of transiently transfected HepG2 cells with $3 \mu \mathrm{g} / \mathrm{mL}$ recombinant human Wnt5a or HepG2 cells, transiently transfected with Frizzled-2-green fluorescent protein (GFP) expression plasmid, shows significantly lower TopFlash activity than HepG2 cells transiently transfected with pcDNA plasmid and treated with PBS. A more pronounced and synergistic decrease in TopFlash activity is seen with the treatment of Wnt5a on HepG2 cells transiently transfected with Frizzled-2-GFP. The transient transfection of Frizzled-2-GFP expression plasmid was measured by immunofluorescence (IF) for GFP that shows approximately $30 \%$ of cells to be transfected at 24 hours after transfection. D: Treatment of pcDNA-transfected HepG2 cells with $3 \mu \mathrm{g} / \mathrm{mL}$ recombinant human Wnt5a or transient expression of Frizzled-2-GFP in HepG2 cells leads to a significant decrease in thymidine incorporation at 48 hours when compared with pcDNA-transfected HepG2 cells treated with PBS. Combining the treatments elicits a more pronounced and synergistic effect. E: Addition of growth factors (GFs; epidermal growth factor and hepatocyte growth factor) to mouse growth medium (MGM) increases thymidine incorporation in primary mouse hepatocytes after 48 hours in culture. The addition of Wnt5a to MGM or growth factor media significantly decreases cell proliferation after 48 hours. F: Representative WB using whole cell lysates from hepatocytes cultured in MGM with Wnt5a for 48 hours shows a notable decrease in levels of $\beta$-catenin, cyclin-D1, and Frizzled-4 expression, and notable increases in Frizzled-2 and Ror 2 when compared with media alone. No changes were observed in total glycogen synthetase kinase (GSK)-3 $\beta$ protein. Equal protein loading was verified by glyceraldehyde-3phosphate dehydrogenase (GAPDH). ${ }^{*} P<0.05, * * P<0.01$. Original magnification, $\times 200$ (C).

Wnt5a treatment led to a modest decrease in total $\beta$-catenin protein and its downstream target, cyclin-D1 (Figure $3 \mathrm{~F}$ ). Total levels of glycogen synthetase kinase- $3 \beta$ remained unchanged. Interestingly, Frizzled-4 levels were reduced, whereas an increase in Frizzled-2 and Ror2 was evident in the presence of Wnt5a. Thus, Wnt5a may be decreasing $\beta$-catenin levels and activity by decreasing Frizzled-4, which favors $\beta$-catenin activation, and increasing Frizzled-2 and Ror2, which favor $\beta$-catenin suppression. ${ }^{16,17,19}$

\section{Generation and Baseline Characterization of Liver-Specific Wnt5a Knockout Mice}

To further elucidate the role of hepatocyte-derived Wnt5a in liver biology, we generated liver-specific Wnt5a knockout mice (Wnt5a-LKO) by interbreeding Wnt5a-floxed mice and Alb-cre transgenic mice. PCR confirmed the concomitant presence of floxed allele and cre-recombinase in Wnt5a-LKO
(Figure 4A). Western blot analysis from Wnt5a-LKO liver lysates showed less Wnt5a expression relative to littermate controls (Figure 4B). The remnant Wnt5a in Wnt5aLKO might be because of its expression in the nonalbumin-expressing nonparenchymal cells. Eight-month-old Wnt5a-LKO mice had normal levels of serum aspartate aminotransferase, alanine aminotransferase, bilirubin, and albumin, comparable to littermate controls (data not shown). Wnt5a-LKO also showed normal liver weight/ body weight ratio as controls (Figure $4 \mathrm{C}$ ). Baseline proliferation examined by IHC for PCNA did not reveal any differences (Figure 4, D and E). $\beta$-Catenin and its downstream target, cyclin-D1, were unchanged in Wnt5a-LKO (Figure 4F). IHC for pericentral expression of $\beta$-catenin targets showed no differences in staining for glutamine synthetase, Cyp1a2, and Cyp2e1 between Wnt5a-LKO and Con (Figure 4G). Therefore, Wnt5a-LKO mice that lack Wnt5a in hepatocytes and cholangiocytes displayed no 

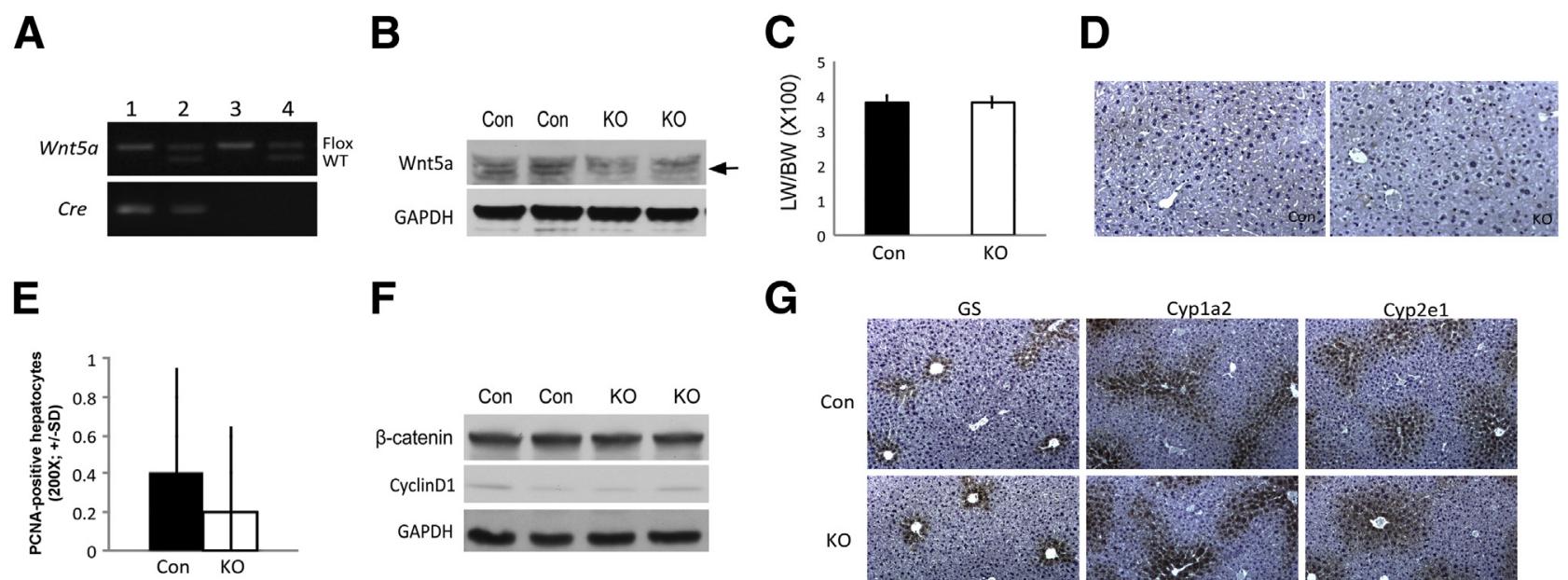

G

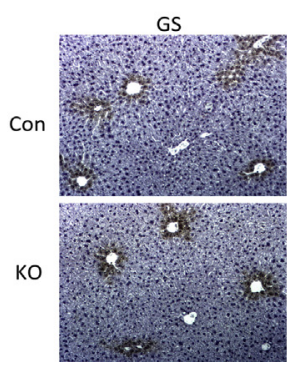

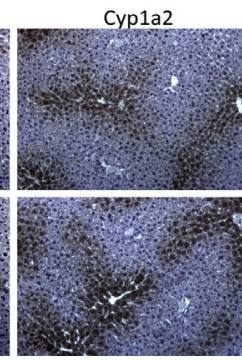

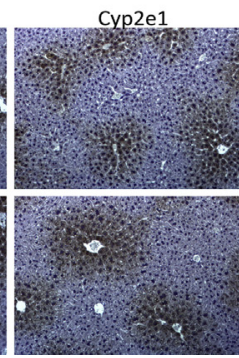

Figure 4 Baseline characterization of Wnt5a-liver-specific knockout (LKO) mice. A: Representative PCR for genotyping mice to identify Wnt5a flox/flox; Albumin-Cre ${ }^{+/-}$or Wnt5a-LKO (lane 1). Mice with genotype Wnt5 ${ }^{\text {flox/flox }} ;$ Albumin-Cre $^{-/-}$or Wnt5a ${ }^{\text {flox/wt }}$;Albumin-Cre ${ }^{-/-}$(lanes 3 and 4 ) were used as controls (Con). B: A Western blot (WB) analysis shows a decrease in Wnt5a expression in livers of Wnt5a-LKO compared with Con. Correct band for Wnt5a protein is shown (arrow). C: Liver weight/body weight (LW/BW) ratio remains unchanged in 8-month-old Wnt5a-LKO compared with Con. D: Immunohistochemistry (IHC) shows only occasional proliferating cell nuclear antigen (PCNA)-positive hepatocytes in both Con and Wnt5a-LKO livers. E: Quantification of PCNA staining shows no difference in the number of positive hepatocytes between Con and Wnt5a-LKO. F: Representative WB shows comparable expression of $\beta$-catenin and cyclin-D1 in the Wnt5a-LKO and Con livers at baseline. G: IHC for glutamine synthetase (GS), Cyp1a2, and Cyp2e1 shows normal pericentral expression in both Con and Wnt5a-LK0 livers. Original magnification: $\times 200$ (D); $\times 100$ (G). GAPDH, glyceraldehyde-3-phosphate dehydrogenase; WT, wild type.

phenotype or alteration in $\beta$-catenin signaling pathway at baseline.

\section{Liver-Specific Wnt5a Knockout Mice Show Comparable Initiation and Termination of Hepatocyte Proliferation during LR}

Next, to address the specific role of Wnt5a in LR, Wnt5a-LKO and Con mice were subjected to PH. PCNA staining at 40 hours and 3 days after $\mathrm{PH}$ showed normal and comparably higher numbers of hepatocytes in the $\mathrm{S}$ phase in both Con and Wnt5aLKO (Figure 5A). Intriguingly and unlike Wls-LKO mice, comparable and low numbers of PCNA-positive hepatocytes were evident at 4, 5, and 14 days in Wnt $5 a$-LKO and Con (Figure 5A). Differences in the numbers of PCNA-positive hepatocytes were statistically insignificant between the two groups at all time points after PH (Figure 5, A and B). Similarly, levels of cyclin-D1 were comparable in the Wnt5a-LKO and Con at all times after PH (Figure 5C).

\section{Wnt5a-LKO Show Adaptive Changes after PH and at Baseline}

Because of no observable differences in either proliferation or cyclin-D1 expression in the absence of Wnt5a from hepatic epithelial cells, we next determined Wnt5a expression at different times after PH in the Wnt5a-LKO and Con. qPCR analysis using total liver tissue homogenate showed that, although there was a decrease in overall Wnt5a expression in Wnt5a-LKO compared with Con at baseline, 24 and 40 hours after $\mathrm{PH}$, this difference diminished at several later time points, such that comparably higher levels of Wnt5a were observed, especially at 3 and 4 days after $\mathrm{PH}$ in Wnt5a-LKO (Figure 6A).

To further assess if $W n t 5 a$-LKO show any additional adaptive changes at baseline, we also examined whole cell lysates from KO and Con for levels of Frizzled-2 and Frizzled-4. Although there were no changes in Frizzled-4 expression, there was a notable decrease in the protein expression of Frizzled-2 in the $W n t 5 a$-LKO livers (Figure 6B). To determine the functional relevance of these changes, we next isolated hepatocytes from Wnt $5 a$-LKO and Con livers by collagenase perfusion and cultured them in the presence of Wnt5a, with and without growth factors, to assess cell proliferation by thymidine incorporation, as described in Materials and Methods. Although hepatocytes from Con mice showed a significant and expected decrease in thymidine incorporation in response to Wnt5a, irrespective of the presence of growth factors, the hepatocytes from Wnt5a-LKO mice were refractory to Wnt5a treatment, although they responded to growth factors (epidermal growth factor and hepatocyte growth factor) (Figure 6, C and D).

Taken together, these data suggest that lack of Wnt5a expression in the Wnt5a-LKO livers may be compensated by down-regulation of inhibitory Frizzled-2 and that Wnt5a secretion after PH in Wnt5a-LKO mice may occur from cells other than hepatocytes to eventually mask its physiological importance in concluding $\beta$-catenin signaling, hepatocyte proliferation, and contribution toward termination of LR.

\section{Discussion}

Several pathways are activated in tandem to initiate LR after $\mathrm{PH}$, and this redundancy not only makes the process efficient 
A
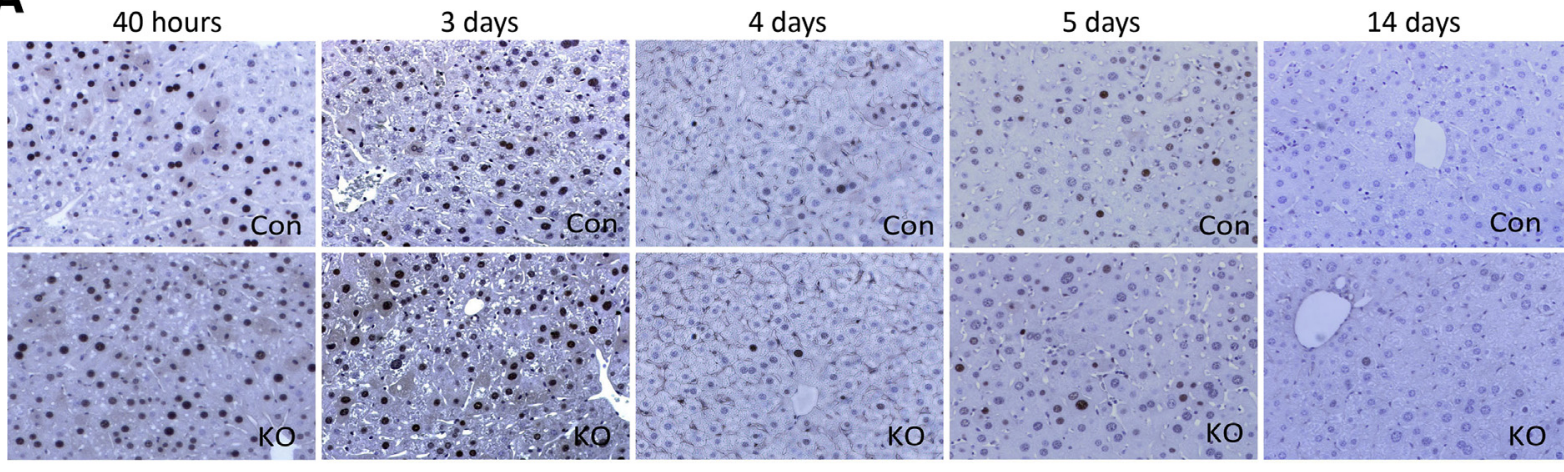

B

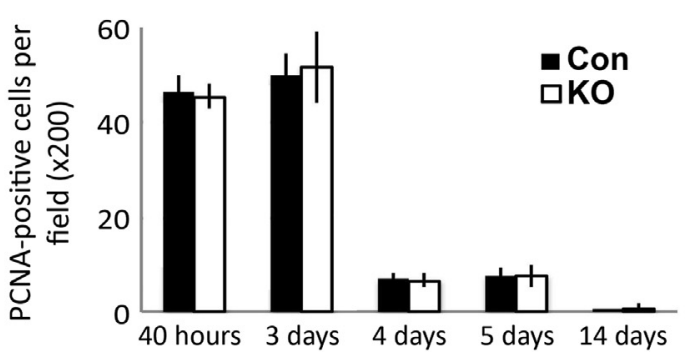

C

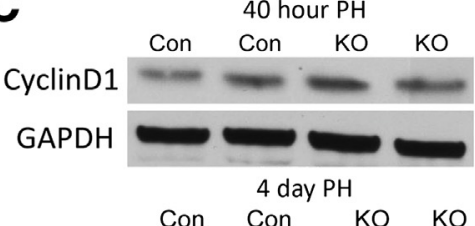

CyclinD1

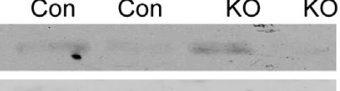

GAPDH
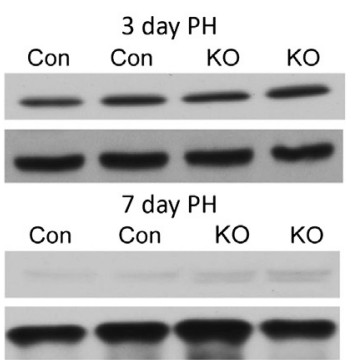

Figure 5 Ablation of Wnt5a in liver epithelial cells has no effect on liver regeneration. A: Immunohistochemistry (IHC) for proliferating cell nuclear antigen (PCNA) shows comparable numbers of positive hepatocytes in the liver-specific knockouts of Wntless (WIs-LKO) and control (Con) at various time points after partial hepatectomy (PH). B: Quantification of PCNA staining shows insignificant differences in the number of positive hepatocytes in Con and WlsLKO at various time points after PH. C: A Western blot analysis shows comparable levels of expression of cyclin-D1 at 40, 72 , and 96 hours after PH in both Con and WIs-LKO. Original magnification, $\times 200($ A). GAPDH, glyceraldehyde-3-phosphate dehydrogenase.

but also ensures its successful execution. ${ }^{2}$ Although it is known for a long time that after surgical loss of hepatic mass, the remaining liver will regenerate to restore the previous mass and LR process will conclude as soon as the prehepatectomy mass is restored. This suggests the existence of the so-called hepatostat in liver biology that will regulate its size on the basis of the need for optimum function. ${ }^{2,20}$ Although pathways such as transforming growth factor- $\beta$ have been proposed to be mito-inhibitory for hepatocytes in culture, loss of its signaling did not have any impact on LR. ${ }^{7,21}$ Recently, an important role of extracellular matrix in counterbalancing hepatic growth and eventually contributing to halt the LR process has been reported. Indeed, conditional knockout (KO) mice of molecules linking extracellular matrix to cell cycle machinery, such as integrin-linked kinase, and components of downstream complexes in the pathway,
A

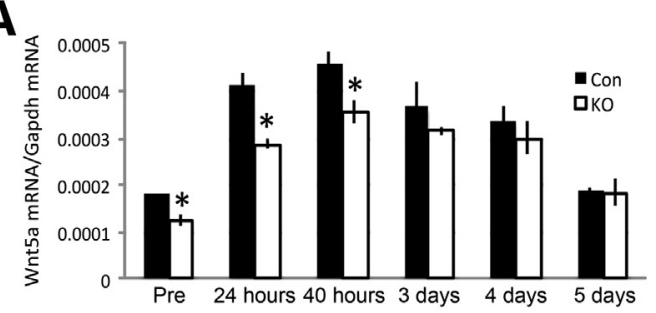

C

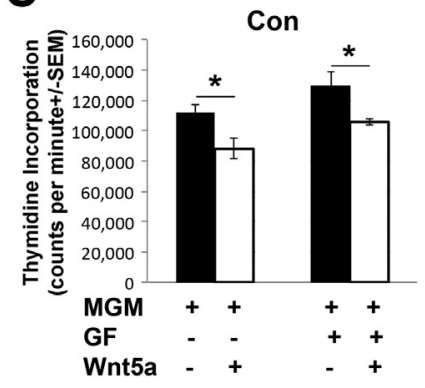

B

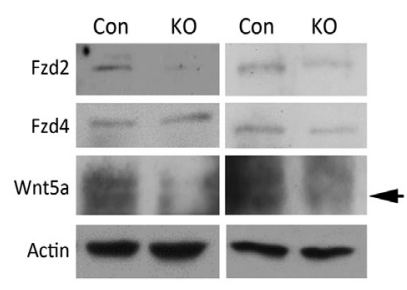

D

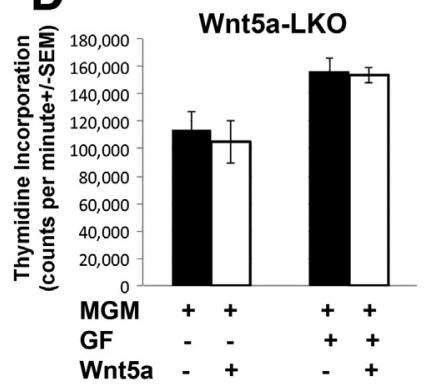

Figure 6 Ablation of Wnt5a in liver epithelial cells leads to adaptive changes during liver regeneration and at baseline. A: Quantitative PCR analysis of Wnt5a expression in total liver tissue shows significantly lower expression of Wnt5a in Wnt5a - liver-specific knockouts (LKOs) at baseline and 24 and 40 hours after partial hepatectomy (PH), whereas no differences are evident at later times, when compared with control (Con). B: A representative Western blot analysis shows lower expression of Frizzled-2 (Fzd2) in lysates from Wnt5aLKO livers compared with Con at baseline. Fzd4 remains unchanged. Equal loading was verified by actin. Correct band for Wnt5a protein is shown (arrow). C: Hepatocytes isolated from littermate Con of a Wnt5a-LKO animal show a significant decrease in thymidine incorporation after Wnt5a treatment in the presence of basal media or growth factor (GF) media. D: Hepatocytes isolated from a Wnt5a-LKO animal respond to GFs, but not to Wnt5a treatment, as seen in a representative thymidine incorporation assay. ${ }^{*} P<0.05$. Gapdh, glyceraldehyde-3-phosphate dehydrogenase; MGM, mouse growth medium. 


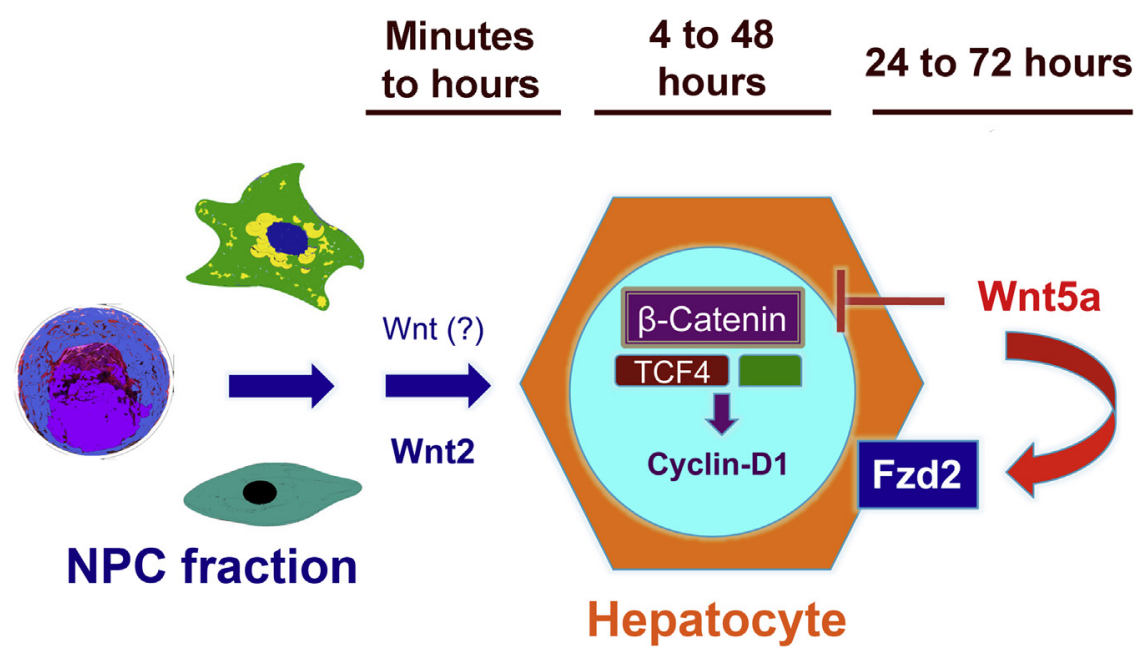

Figure 7 Wnt/ $\beta$-catenin signaling and liver regeneration. Immediately after partial hepatectomy, nonparenchymal cells like endothelial cells, macrophages, and possibly stellate cells release Wnt2 and yet other unidentified Wnt proteins at 1 to 6 hours after hepatectomy. These cells act on hepatocytes in a paracrine manner to activate the $\beta$-catenin-T-cell factor (TCF) 4 complex as early as 4 hours after hepatectomy to induce cyclin-D1 (CCND1) gene at 12 to 24 hours. Cyclin-D1 facilitates $G_{1}$ to $S$-phase transition of hepatocytes to induce hepatocyte proliferation at 36 to 48 hours. At 24 hours after hepatectomy, Wnt5a and Frizzled-2 (Fzd2) are induced and, in an autocrine manner, terminate $\beta$-catenin signaling in hepatocytes to suppress hepatocyte proliferation and terminate liver regeneration. NPC, non-parenchymal cell fraction. such as particularly interesting new cysteine-histidine-rich protein, showed defects in termination of LR after being subjected to $\mathrm{PH}^{8,22}$ Eventually, it is likely that the LR termination signal may not represent a single entity in the form of a molecular mechanism, but may, in the end, be a function of a cumulative effect of negative regulators of various hepatic mitogenic pathways that may be contributing in tandem to stop LR.

On the basis of such speculation, we took an alternative approach to address the termination mechanisms of LR. Because $\beta$-catenin is an essential proproliferative signaling factor that triggers LR, identification of negative regulators of $\beta$-catenin signaling during stages of LR, when hepatocyte proliferation is coming to a halt, might thus provide useful insights into the understanding of potential contributory mechanisms toward eventual termination of LR. The role of $\beta$-catenin in initiation of LR as one of the major pathways is unquestionable, because its loss alone in hepatocytes causes a significant diminution in the numbers of hepatocytes entering the $\mathrm{S}$ phase after $\mathrm{PH}$ because of reduced cyclin-1 expression. ${ }^{3,4,10}$ Conversely, activation of $\beta$-catenin through either a genetic approach or an exogenous Wnt stimulation fuels the process of LR. ${ }^{13,23-25}$ In the current study, we identified a modest, but reproducible, defect in LR termination in mice that could not secrete Wnt proteins from hepatocytes.

Wntless protein is a cargo receptor, which is dedicated in transporting post-translationally modified Wnt proteins in and outside the cell. ${ }^{26}$ Its loss prevents Wnt secretion and hence is a way to generate the Wntless phenotype. ${ }^{9}$ Previously, use of liver-specific $W l s$-LKO allowed us to study any role of hepatic epithelial cell-derived Wnt proteins in initiation of LR and metabolic zonation. ${ }^{10}$ Interestingly, continued examination of $\beta$-catenin signaling, cyclin-D1 expression, and markers of $\mathrm{S}$ phase in the Wls-LKO mice revealed a prolonged hepatocyte proliferative program, suggesting that hepatocytes may be the source of at least some termination signal for $\beta$-catenin signaling at the time when its activation or hepatocyte proliferation is not deemed necessary anymore. Because the Wntless protein is specific only for Wnt secretion, it was further clear that hepatocytes might be secreting a Wnt, whose lack of secretion in $W l s$ LKO led to a prolonged hepatocyte proliferation, even though the phenotype was transient. That led us to identify Wnt5a, a protypical bifunctional molecule that is known to both enhance and inhibit $\beta$-catenin signaling in a contextdependent manner, to be differentially regulated during LR. ${ }^{17}$ What was intriguing was that the Wnt5a increase occurred almost immediately after $\beta$-catenin activation and relatively early during LR, but did not precede $\beta$-catenin activation, which is evident at 1 to 6 hours after $\mathrm{PH}$ in mice. ${ }^{10,27}$ Although there was a modest increase in Wnt5a evident in LR at 1 and 12 hours, there was either no change or, in fact, down-regulation of Frizzled-2 expression at these times. It was only at 24 hours that Wnt5a and Frizzled-2 were simultaneously induced significantly after PH. In fact, Wnt5a was also observed in the conditioned media obtained from cultured hepatocytes that were isolated from regenerating livers at 48 hours after $\mathrm{PH}$ and cultured in vitro for 24 hours. As expected, Wnt5a was absent in the media from regenerating Wntless hepatocytes. The relevance of the Wnt5a-Frizzled-2 axis in suppressing $\beta$-catenin and cell proliferation was also evident in primary normal hepatocytes and liver tumor cells.

Wnt5a can transduce signals through both canonical and noncanonical signaling mechanisms. ${ }^{17}$ The noncanonical Wnt signaling pathway includes those pathways that use downstream effectors other than $\beta$-catenin-TCF/lymphoid enhancement factor and actually may, at the same time, inhibit $\beta$-catenin-dependent signaling. Wnt5a can activate the $\mathrm{Wnt} / \mathrm{Ca}^{2+}$ pathway or Rac signaling, especially when it binds to receptors, such as Frizzled-2 and Ror2. ${ }^{16}$ Wnt5a is known to counterbalance $\beta$-catenin-TCF activity for proper formation of the dorsoventral axis during Xenopus. ${ }^{28}$ In fact, embryos genetically depleted of Wnt-5 showed hyperdorsalization and axis-duplication phenotypes because of 
increased $\beta$-catenin accumulation and activation. Wnt5a, through receptor Ror2, can also activate Jun N-terminal kinase signaling. ${ }^{19,29}$ However, Wnt5a in the presence of Frizzled-4 receptor can activate $\beta$-catenin pathway, leading to expression of its downstream genes. ${ }^{17}$ In primary hepatocytes and liver cancer cells, Wnt5a treatment led to decreased $\beta$-catenin-TCF reporter activity, which coincided with decreased Frizzled-4 and increased Frizzled-2 and Ror2 expression, supporting a switch from $\beta$-catenin activation to $\beta$-catenin inhibitory signaling. Although the exact mechanism is still being investigated, Wnt5a, by default, inhibits $\beta$-catenin in the context of hepatocyte culture and LR. The tumor suppressor function of Wnt5a through $\beta$-catenin inhibition has been shown in thyroid cancer. ${ }^{30}$ In colon cancer also, Wnt5a can inhibit constitutively active $\beta$-catenin in activated protein $\mathrm{C}$-mutated cells in an autocrine manner. ${ }^{31}$ Wnt5a was also shown to decrease hepatocellular carcinoma growth in vitro, and many hepatocellular carcinoma tissues showed loss of Wnt5a and/or Ror2 expression that correlated with $\beta$-catenin stabilization, also supporting an antagonistic role of Wnt5a in $\beta$-catenin activation. ${ }^{32,33}$

To directly address its role in hepatocytes, we generated cell Wnt5a conditional knockout mice. Wnt $5 a$-LKO livers express less Wnt5a than Con at baseline, suggesting that other liver cell populations also express Wnt5a. These mice lacked any overt phenotype at baseline in terms of liver size, injury, or zonation. Surprisingly, Wnt5a-LKO exhibited no alteration in LR kinetics after PH. qPCR analysis for Wnt5a expression in total liver tissue showed modest, but significant, differences between Con and Wnt5a-LKO at 24 and 40 hours after PH, but no differences were evident at any later time points. These data suggest that other liver cell populations can secrete Wnt5a at baseline and also after PH and, thus, may be able to compensate for liver epithelial cell-derived Wnt5a. We also observed a basal decrease in Frizzled-2 expression in the $W n t 5 a$-LKO hepatocytes. This adaptive change prevented $W n t 5 a$-LKO hepatocytes from responding to exogenous Wnt5a. Finally, another possible explanation for differences in the phenotypes in regeneration in Wls-LKO versus Wnt5aLKO may be that, although none of the Wnt proteins can be secreted by hepatocytes in $W l s$-LKO, only Wnt5a is deficient in the Wnt5a-LKO, making compensation relatively effortless in the latter. Collectively, these explanations may account for a lack of phenotype in the Wnt5a-LKO mice.

\section{Conclusions}

Thus, a model emerges from all studies of $\beta$-catenin activation and termination in the LR process (Figure 7). Under the influence of certain Wnt signals, whose identity is not completely clear yet, $\beta$-catenin is activated relatively early ( 1 to 6 hours) after $\mathrm{PH}$ in mice. ${ }^{10} \mathrm{Wnt} 2$ has previously been shown to be released from the endothelial cells in the liver; macrophages have also been shown to be a source of Wnt proteins, and these collectively activate $\beta$-catenin signaling in hepatocytes during LR after $\mathrm{PH}$ in a paracrine manner. ${ }^{10,34}$ This induces expression of cyclin-D1, ${ }^{3,4}$ which is known to eventually stimulate $G_{1}$ to $S$ phase transition in hepatocytes to initiate the process of hepatocyte proliferation. ${ }^{35}$ In the current study, we show that Wnt5a is released from hepatocytes at 24 hours after $\mathrm{PH}$, and at the same time, there is enhanced expression of Frizzled-2. Thus, the Wnt5a-Frizzled-2 axis terminates $\beta$-catenin activity during LR, when its activation is no longer required. This appears to be an autocrine process whereby hepatocytes themselves sense the need for curbing the signaling. Termination mechanisms are initiated early in the process of LR, especially when taking into account that hepatocyte proliferation does not itself become apparent until 36 to 48 hours after PH. Thus, it seems that the initiation and termination of LR require a transition from positive to negative regulation within a signaling pathway to ensure it to be a seamless process. Hence, it is likely that, from the perspective of a signaling pathway such as Wnt, LR is truly a cascade, whereby its activation and termination are temporally predetermined in a true physiological context. Furthermore, just like we appreciate a redundancy in signaling for initiation of LR, there may be several mechanisms in tandem to properly terminate a signaling mechanism to eventually contribute to cessation of LR. 2,20,36 This was evident in Wnt5a-LKO, where loss of ability of hepatocytes to secrete Wnt5a was compensated by reduced Frizzled-2 expression and by its release from another cell source during LR. Loss of these termination signals may be evident in dysregulated hepatic growth, such as in tumors. Indeed, Wnt5a loss leads to enhanced $\beta$-catenin signaling in hepatocellular carcinoma. ${ }^{32,33}$ Thus, there may be a comparable pressure on both ends to maintain liver size, again validating the existence of hepatostat that may be essential for health. ${ }^{2}$

\section{References}

1. Monga SP: Role and regulation of beta-catenin signaling during physiological liver growth. Gene Expr 2014, 16:51-62

2. Michalopoulos GK: Principles of liver regeneration and growth homeostasis. Compr Physiol 2013, 3:485-513

3. Sekine S, Gutierrez PJ, Lan BY, Feng S, Hebrok M: Liver-specific loss of beta-catenin results in delayed hepatocyte proliferation after partial hepatectomy. Hepatology 2007, 45:361-368

4. Tan X, Behari J, Cieply B, Michalopoulos GK, Monga SP: Conditional deletion of beta-catenin reveals its role in liver growth and regeneration. Gastroenterology 2006, 131:1561-1572

5. Overturf K, al-Dhalimy M, Ou CN, Finegold M, Grompe M Serial transplantation reveals the stem-cell-like regenerative potential of adult mouse hepatocytes. Am J Pathol 1997, 151: $1273-1280$

6. Overturf K, Al-Dhalimy M, Finegold M, Grompe M: The repopulation potential of hepatocyte populations differing in size and prior mitotic expansion. Am J Pathol 1999, 155:2135-2143

7. Satoh M, Yamazaki M: Tumor necrosis factor stimulates DNA synthesis of mouse hepatocytes in primary culture and is suppressed by transforming growth factor beta and interleukin 6. J Cell Physiol 1992, 150:134-139

8. Apte U, Gkretsi V, Bowen WC, Mars WM, Luo JH, Donthamsetty S, Orr A, Monga SP, Wu C, Michalopoulos GK: Enhanced liver 
regeneration following changes induced by hepatocyte-specific genetic ablation of integrin-linked kinase. Hepatology 2009, 50:844-851

9. Carpenter AC, Rao S, Wells JM, Campbell K, Lang RA: Generation of mice with a conditional null allele for Wntless. Genesis 2010, 48:554-558

10. Yang J, Mowry LE, Nejak-Bowen KN, Okabe H, Diegel CR, Lang RA, Williams BO, Monga SP: Beta-catenin signaling in murine liver zonation and regeneration: a Wnt-Wnt situation! Hepatology 2014, 60:964-976

11. Postic C, Shiota M, Niswender KD, Jetton TL, Chen Y, Moates JM, Shelton KD, Lindner J, Cherrington AD, Magnuson MA: Dual roles for glucokinase in glucose homeostasis as determined by liver and pancreatic beta cell-specific gene knock-outs using Cre recombinase. J Biol Chem 1999, 274:305-315

12. Yun K, Ajima R, Sharma N, Costantini F, Mackem S, Lewandoski M, Yamaguchi TP, Perantoni AO: Non-canonical Wnt5a/Ror2 signaling regulates kidney morphogenesis by controlling intermediate mesoderm extension. Hum Mol Genet 2014, 23:6807-6814

13. Nejak-Bowen KN, Thompson MD, Singh S, Bowen WC Jr, Dar MJ, Khillan J, Dai C, Monga SP: Accelerated liver regeneration and hepatocarcinogenesis in mice overexpressing serine- 45 mutant betacatenin. Hepatology 2010, 51:1603-1613

14. Maye P, Zheng J, Li L, Wu D: Multiple mechanisms for Wnt11mediated repression of the canonical Wnt signaling pathway. J Biol Chem 2004, 279:24659-24665

15. Topol L, Jiang X, Choi H, Garrett-Beal L, Carolan PJ, Yang Y: Wnt-5a inhibits the canonical Wnt pathway by promoting GSK-3-independent beta-catenin degradation. J Cell Biol 2003, 162:899-908

16. Sato A, Yamamoto H, Sakane H, Koyama H, Kikuchi A: Wnt5a regulates distinct signalling pathways by binding to Frizzled2. EMBO J 2010, 29:41-54

17. Mikels AJ, Nusse R: Purified Wnt5a protein activates or inhibits betacatenin-TCF signaling depending on receptor context. PLoS Biol 2006, 4:e115

18. Pullara F, Guerrero-Santoro J, Calero M, Zhang Q, Peng Y, Spahr H, Kornberg GL, Cusimano A, Stevenson HP, Santamaria-Suarez H, Reynolds SL, Brown IS, Monga SP, Van Houten B, Rapic-Otrin V, Calero G, Levine AS: A general path for large-scale solubilization of cellular proteins: from membrane receptors to multiprotein complexes. Protein Expr Purif 2013, 87:111-119

19. Mikels A, Minami Y, Nusse R: Ror2 receptor requires tyrosine kinase activity to mediate Wnt5A signaling. J Biol Chem 2009, 284:30167-30176

20. Michalopoulos GK: Advances in liver regeneration. Expert Rev Gastroenterol Hepatol 2014, 8:897-907

21. Oe S, Lemmer ER, Conner EA, Factor VM, Leveen P, Larsson J, Karlsson S, Thorgeirsson SS: Intact signaling by transforming growth factor beta is not required for termination of liver regeneration in mice. Hepatology 2004, 40:1098-1105

22. Donthamsetty S, Bhave VS, Mars WM, Bowen WC, Orr A, Haynes MM, Wu C, Michalopoulos GK: Role of PINCH and its partner tumor suppressor Rsu-1 in regulating liver size and tumorigenesis. PLoS One 2013, 8:e74625

23. Fanti M, Singh S, Ledda-Columbano GM, Columbano A, Monga SP: Tri-iodothyronine induces hepatocyte proliferation by protein kinase
A-dependent beta-catenin activation in rodents. Hepatology 2014, 59: 2309-2320

24. Goessling W, North TE, Loewer S, Lord AM, Lee S, Stoick-Cooper CL, Weidinger G, Puder M, Daley GQ, Moon RT, Zon LI: Genetic interaction of PGE2 and Wnt signaling regulates developmental specification of stem cells and regeneration. Cell 2009, 136:1136-1147

25. Goessling W, North TE, Lord AM, Ceol C, Lee S, Weidinger G, Bourque C, Strijbosch R, Haramis AP, Puder M, Clevers H, Moon RT, Zon LI: APC mutant zebrafish uncover a changing temporal requirement for wnt signaling in liver development. Dev Biol 2008, 320: $161-174$

26. Banziger C, Soldini D, Schutt C, Zipperlen P, Hausmann G, Basler K: Wntless, a conserved membrane protein dedicated to the secretion of Wnt proteins from signaling cells. Cell 2006, 125:509-522

27. Nakamura I, Fernandez-Barrena MG, Ortiz-Ruiz MC, Almada LL, Hu C, Elsawa SF, Mills LD, Romecin PA, Gulaid KH, Moser CD, Han JJ, Vrabel A, Hanse EA, Akogyeram NA, Albrecht JH, Monga SP, Sanderson SO, Prieto J, Roberts LR, FernandezZapico ME: Activation of the transcription factor GLI1 by WNT signaling underlies the role of SULFATASE 2 as a regulator of tissue regeneration. J Biol Chem 2013, 288:21389-21398

28. Westfall TA, Brimeyer R, Twedt J, Gladon J, Olberding A, FurutaniSeiki M, Slusarski DC: Wnt-5/pipetail functions in vertebrate axis formation as a negative regulator of Wnt/beta-catenin activity. J Cell Biol 2003, 162:889-898

29. Oishi I, Suzuki H, Onishi N, Takada R, Kani S, Ohkawara B, Koshida I, Suzuki K, Yamada G, Schwabe GC, Mundlos S, Shibuya H, Takada S, Minami Y: The receptor tyrosine kinase Ror2 is involved in noncanonical Wnt5a/JNK signalling pathway. Genes Cells 2003, 8:645-654

30. Kremenevskaja N, von Wasielewski R, Rao AS, Schofl C, Andersson T, Brabant G: Wnt-5a has tumor suppressor activity in thyroid carcinoma. Oncogene 2005, 24:2144-2154

31. MacLeod RJ, Hayes M, Pacheco I: Wnt5a secretion stimulated by the extracellular calcium-sensing receptor inhibits defective Wnt signaling in colon cancer cells. Am J Physiol Gastrointest Liver Physiol 2007, 293:G403-G411

32. Geng M, Cao YC, Chen YJ, Jiang H, Bi LQ, Liu XH: Loss of Wnt5a and Ror2 protein in hepatocellular carcinoma associated with poor prognosis. World J Gastroenterol 2012, 18:1328-1338

33. Yuzugullu H, Benhaj K, Ozturk N, Senturk S, Celik E, Toylu A, Tasdemir N, Yilmaz M, Erdal E, Akcali KC, Atabey N, Ozturk M: Canonical Wnt signaling is antagonized by noncanonical Wnt5a in hepatocellular carcinoma cells. Mol Cancer 2009, 8:90

34. Ding BS, Nolan DJ, Butler JM, James D, Babazadeh AO, Rosenwaks Z, Mittal V, Kobayashi H, Shido K, Lyden D, Sato TN, Rabbany SY, Rafii S: Inductive angiocrine signals from sinusoidal endothelium are required for liver regeneration. Nature 2010, 468:310-315

35. Rickheim DG, Nelsen CJ, Fassett JT, Timchenko NA, Hansen LK, Albrecht JH: Differential regulation of cyclins D1 and D3 in hepatocyte proliferation. Hepatology 2002, 36:30-38

36. Michalopoulos GK: Liver regeneration after partial hepatectomy: critical analysis of mechanistic dilemmas. Am J Pathol 2010, 176: $2-13$ 